\title{
Spatial and Temporal Land Cover Changes in the Simen Mountains National Park, a World Heritage Site in Northwestern Ethiopia
}

\author{
Menale Wondie $^{1}{ }^{1}$, Werner Schneider ${ }^{2}$, Assefa M. Melesse ${ }^{3}$ and Demel Teketay ${ }^{4}$ \\ 1 Adet Agricultural Research Center, P.O. Box 08, Bahar Dar, Ethiopia \\ 2 University of Natural Resources and Applied Life Science, A-1180 Vienna, Austria; \\ E-Mail: werner.schneider@boku.ac.at \\ 3 Department of Earth and Environment, Florida International University, ECS 339, 11200 S.W.8th \\ Street, Miami, FL 33199, USA; E-Mail: melessea@ fiu.edu \\ 4 Okavango Research Institute, University of Botswana, Shorobe Road, Private Bag 285, Maun, \\ Botswana; E-Mail: demel.fanta@mopipi.ub.bw \\ * Author to whom correspondence should be addressed; E-Mail: menalewondie @ yahoo.com; \\ Tel.: +251-583-380-828; Fax: +251-583-380-235.
}

Received: 5 January 2011; in revised form: 11 February 2011 / Accepted: 23 February 2011 / Published: 8 April 2011

\begin{abstract}
The trend of land cover (LC) and land cover change (LCC), both in time and space, was investigated at the Simen Mountains National Park (SMNP), a World Heritage Site located in northern Ethiopia, between 1984 and 2003 using Geographical Information System (GIS) and remote sensing (RS). The objective of the study was to generate spatially and temporally quantified information on land cover dynamics, providing the basis for policy/decision makers and resource managers to facilitate biodiversity conservation, including wild animals. Two satellite images (Landsat TM of 1984 and Landsat ETM+ of 2003) were acquired and supervised classification was used to categorize LC types. Ground Control Points were obtained in field condition for georeferencing and accuracy assessment. The results showed an increase in the areas of pure forest (Erica species dominated) and shrubland but a decrease in the area of agricultural land over the 20 years. The overall accuracy and the Kappa value of classification results were 88 and $85 \%$, respectively. The spatial setting of the LC classes was heterogeneous and resulted from the biophysical nature of SMNP and anthropogenic activities. Further studies are suggested to evaluate the existing LC and LCC in connection with wildlife habitat, conservation and management of SMNP.
\end{abstract}


Keywords: change analysis; GIS; land cover; land cover change; Landsat; remote sensing; supervised classification

\section{Introduction}

Starting from the beginning of civilization, human-beings have deliberately managed and converted the landscape to utilize and exploit natural resources mainly to derive basic needs such as food, shelter, fresh water, and pharmaceutical products [1]. However, the increase in population has proportionally increased the demand for resources for centuries; leading to the conversion of natural environmental conditions. Ecological processes and human interventions are facilitating ecosystem changes as a whole and land cover change (LCC) in particular. In particular term, LCC is a dynamic phenomenon occurring within the interface between human agricultural and ecological systems [2]. In most parts of the world, agriculture is the primary driver of land use change. The main pressure is to convert forests to agricultural uses in order to meet the increasing demands caused by human population growth. Scholes and Breeman [3] indicated that in addition to fossil fuels, the conversion of natural vegetation to agriculture is partially responsible for changes in the atmospheric composition and climate conditions. Despite the importance of landscape conversion to fulfill basic needs of humankind, LCCs such as deforestation have been recognized as major problems in the world and are drivers of global warming $[4,5]$, which result in negative consequences for life on earth.

LCC may be the most significant agent of global change influencing hydrology, climate, and global biogeochemical cycles. The negative consequences of LCC are changes of global and regional climates, the global biogeochemical cycles such as carbon, nitrogen and water, biodiversity as well as a change of the ecosystem functions as a whole [1,6-8]. It is a continuing process, a challenging consequence and an environmental problem, especially in tropical regions where deforestation is occurring at an alarming rate [3].

Information on LCC induced by population pressure and other external factors is required as a basis for counter measures. Up-to-date global land cover data sets are necessary for various global change research studies, including climate change, biodiversity conservation, ecosystem assessment and environmental modeling [9]. Since land cover is the actual distribution of physical and biological features of the land surface, up-to-date information on the status of the land surface is crucial for environmental planning and management reasons [10]. The resource managers can superimpose the land cover map to existing management and conservation zone maps and use it as a planning tool for the optimization of protection sites (e.g., in SMNP) by providing information on the status of wildlife and natural resources [11]. Remotely sensed image data are widely used in terrestrial, oceanographic and atmospheric applications such as land cover mapping, environmental modeling and monitoring, updating of geographical databases of the specific area, etc. [12]. Satellite remote sensing (RS) and Geographical Information System (GIS) have been widely applied in identifying and analyzing LCC for different purposes [13].

For sustainable management and decision making processes related to natural resources, knowledge about the ecosystem on both the temporal and the spatial scale is required [14]. This managerial 
decision on resources has to be based on change analysis, which is the comparison of the current status with past events.

The physical, social and economic situations in Ethiopia have contributed to the degradation of resources. There are different types of land cover formed by both human activities and natural factors over the last centuries. Population pressure accompanied by sedentary agriculture, extensive animal husbandry (livestock herding), settlement and socio-political instability have resulted in heavy deforestation, forest fragmentation, loss of biodiversity and undesirable changes in the natural ecosystem, including LCC [15].

Tatem et al. [16] noted that accurate information on land cover is required for both scientific research and undertaking management interventions. The assessment of conversion of the land cover types due to socio-economic and ecological factors helps to qualify and quantify its (Land cover change determines or has an implication on the potential of the resource change) status with respect to resource changes. Particularly, for SMNP, it is necessary to know which kind of land conversion is a threat to the wildlife habitat so that further decision making processes can be initiated to undertake management intervention for biodiversity conservation. If changes are assessed both quantitatively and qualitatively, the management intervention as well as the decision making process can be planned to meet the main objectives of the SMNP.

The general objective of the study was to generate spatially and temporally quantified information on land cover dynamics and provide basic information for policy/decision makers and for resource managers to undertake mitigation measures in areas at risk where the wildlife habitat is threatened. This includes, primarily, biodiversity conservation and management of the park. The specific objective of this study was to identify and quantify the rate of spatio-temporal LCC between 1984 and 2003. The study also helps to produce land cover map to show the overall situation of the heritage site and provides basic information for further study.

\section{Materials and Methods}

\subsection{Study Site}

The SMNP is situated approximately between $13^{\circ} 09^{\prime}$ and $13^{\circ} 12^{\prime} \mathrm{N}$ and $38^{\circ} 00^{\prime}$ and $38^{\circ} 12^{\prime} \mathrm{E}$ [17] (Figure 1). The nearest town is Debark in the North Gonder Zone, northwestern Ethiopia. It is about $920 \mathrm{~km}$ north of Addis Ababa. The altitude of SMNP ranges from 1,900 to 4,430 m. It has an Afro-alpine undulating grassland plateau with steep escarpments lying towards both the north and east direction, giving spectacular views of peaks and canyons of areas found outside the boundary of the park. There are V-and U-shaped canyons due to geological processes. The rainfall pattern is characterized by a single rainy season, whereby the highest amount of precipitation is between June and September [18]. The average annual rainfall is between 1,350 and 1,550 $\mathrm{mm}$ and varies with altitude $[18,19]$. Temperature ranges from -2 to $18{ }^{\circ} \mathrm{C}$. 
Figure 1. Location of the study area.

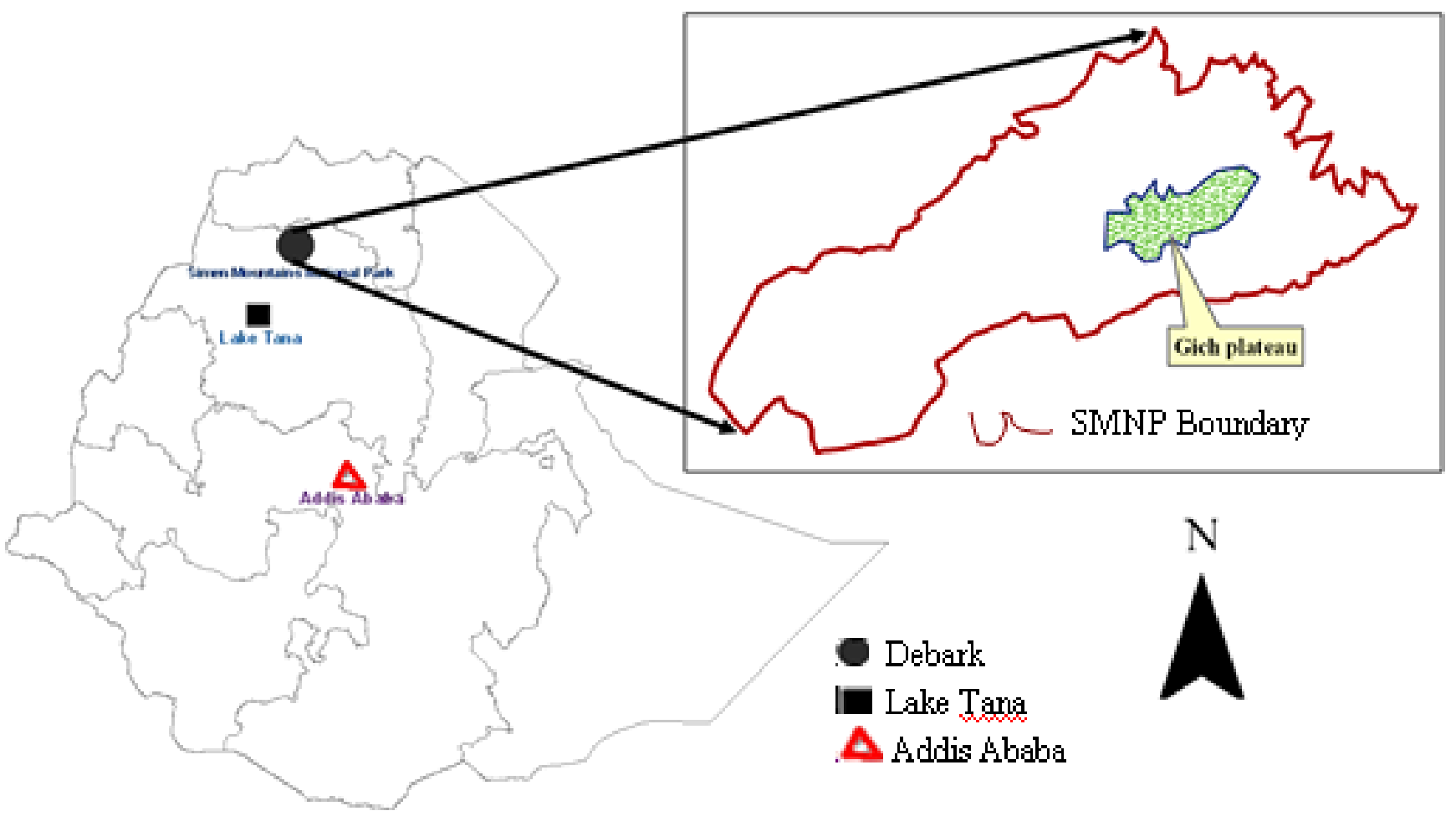

Due to differences in land use practice, geological events, topography and climate, different soil types are found in the SMNP. Andosol type of soil is found on uncultivated land above 3,000 m, whereas below 3,000 $\mathrm{m}$ and on cultivation land above $3,000 \mathrm{~m}$, the dominant type of soil are Phaeozem, Vertisol, Luvisol, Regosol and Leptosol [18]. The grassland is dominantly covered with Andosol. The very small area, with no agricultural potential is attributed to Fluvisol. The Simen was made up of thick basalt deposited on Mesozoic sandstone and limestone, Precambrian crystalline basement, and harder rocks on the foot of the escarpment [19].

The park was officially established, delineated and legally gazetted on 31 October 1969 by order No. 59 in the Negarit Gazeta [19]. Initially, it was proposed to cover an approximate area of $225 \mathrm{~km}^{2}$. According to Hurni and Ludi [18], the SMNP was estimated to cover 13,900 ha (139 $\left.\mathrm{km}^{2}\right)$. During the study of 2006, it covered an area of 13,907 ha [11]. Because of its rich biodiversity, high number of endemic species and special bio-physical features, SMNP was one of the country's first sites to be inscribed and listed as a World Heritage Site by UNESCO in 1978 [19].

\subsection{Methods}

Two methods, namely analysis of Landsat satellite image and field observations, were employed in the study. The analysis of Landsat Satellite Images of TM 1984 and ETM+ 2003 was carried out to identify LCC while the field observations (July-September 2006) were performed to collect reference information for image analysis and verification of automated classification. 


\subsection{Data Collection}

Two satellite images (Landsat TM of 1984 and Landsat ETM+ of 2003) were acquired from Earth Science Data Interface (ESDI) [12]. A Digital Elevation Model (DEM) was needed for georeferencing the 2003 Landsat image and for producing 3D perspective views of the resulting thematic maps. Shuttle Radar Topographic Mission (SRTM) DEM $90 \mathrm{~m}$ was acquired from CGIAR-CSI that has no areas of missing Z values. The specifications of this SRTM data set are: (C) 2004 CGIAR-CSI, Product: SRTM 90-m DEM, Latitude: $10^{\prime}$ to $15^{\prime} \mathrm{N}$, Longitude: $35^{\prime}$ to $40^{\prime} \mathrm{E}$, Center Point: Latitude 12.50 ' , Longitude $37.50^{\prime} \mathrm{E}$ and, Tile: $\mathrm{X}=44$ and Tile $\mathrm{Y}=10$.

Field observations were carried out to obtain Ground Control Points (GCPs) for georeferencing the images, to understand the features of the different LC classes, support visual interpretation of the images and select reference areas [consisting of training areas (for supervised classification) and test areas (for accuracy assessment)]. All reference areas were documented by photos and localized by GPS measurements. Representative samples were taken from agricultural land, grassland/pasture, forest, shrubland, settlement. The number of representative training samples for agriculture, mixed forest, pure forest, shrubland and grassland were 31, 19, 22, 7 and 25, respectively. GPS readings were taken for each sample point with an accuracy varying from 7 to $12 \mathrm{~m}$. The land cover categorization scheme was based on Tso and Mather [12] and Amsalu et al. [21] with some modifications (Table 1).

Table 1. Land cover classes used in the classification scheme.

\begin{tabular}{ll}
\hline Cover class & Characterization features \\
\hline $\begin{array}{l}\text { Agricultural land } \\
\text { /cultivation }\end{array}$ & $\begin{array}{l}\text { Cultivated and fallow land has a characteristic pattern, for example sharp } \\
\text { edges between fields. Dark to grey color in the Landsat image (4, 3 and 2 } \\
\text { color composition), unless the land lies fallow [18,21] } \\
\text { Land under permanent pasture and grassland, grassland mixed with Lobelia } \\
\text { species. Homogeneous, no pattern compared to agricultural land [18] }\end{array}$ \\
$\begin{array}{l}\text { Mixed and matured } \\
\text { natural forest }\end{array}$ & $\begin{array}{l}\text { Natural forests and woodlands with a composition of different tree species } \\
\text { Pure Forest }\end{array}$ \\
$\begin{array}{l}\text { One dominating species (Ericaceous species, >95\% of the mix) [18] } \\
\text { Shrubland }\end{array}$ & $\begin{array}{l}\text { Shrubs, bushes and young tree species, bright red on the Landsat 4, 3 and 2 } \\
\text { color composite [18] }\end{array}$ \\
\hline
\end{tabular}

\subsection{Data Analyses}

The TM 1984 image was georeferenced by the supplier using nearest neighbor resampling technique [22]. The Landsat ETM+ 2003 image was georeferenced using 69 GCPs. The 2003 ETM+ Landsat image was rectified t o the UTM projection system WGS-1984-UTM-Zone 37N. The total RMS error was 0.95 pixels, an error of $28.5 \mathrm{~m}$. The residual of individual GCPs vary from 0.16 to 1.76 pixels. Due to the rugged topographic nature of the area and the existence of limited information on GCPs, the RMS error is assumed to be satisfactory. The orthorectification resampling method used is nearest neighbor. The method used to classify the Landsat images according to LC was supervised classification using ERDAS Imagine 9.1 image processing software. Pixels were clustered into the categories of agriculture, mixed natural forest, pure forest (dominant by $>95 \%$ Ericaceous species), 
shrubland and/or young species of other trees and grassland. ArcGIS 9.1 software was used for spatial analysis.

Areas of Interests (AOIs) were selected as training areas (polygons) for image classification. The TM 1984 and ETM+ 2003 datasets were classified with the same number and size of AOIs of the respective individual land cover types. Number, size and distribution of individual AOIs were variable within and between LC classes depending on the location, information and data availability. The number of sample AOIs (from field work, visual interpretation and the map) for agriculture, natural mixed forest, pure forest, shrubland, grassland and unclassified (shadow) was 128, 50, 53, 65, 56 and 34, respectively. A total of 386 AOIs were used for classification. The decision rule used in supervised classification was the maximum likelihood classifier algorithm. Equal a-priori probabilities of the individual categories were assumed.

The accuracy of the classification and the output of land cover mapping were assessed using representative samples taken during field observations. The accuracy statistics provides objective information about the quality of the LC classification. Accuracy assessment helps to identify misidentifications as well as understand and measure how errors tend to be spatially correlated. Hence, to control the quality of the classification output, accuracy assessment between the representative samples of LC categories in field data versus the automated classification was conducted. Accuracy assessment was carried out using error matrix techniques. The error matrix is one of the tools used for classification accuracy assessment in order to compare known data (field data) with the corresponding results of automated classification [23]. It helps to compare two thematic maps in a tabular form that describes the accuracy of a classified map with respect to a reference map. In remote sensing image analysis, the two thematic maps are often a "ground truth" map (the reference map) and a map derived from automated image classification [23]. Based on the field survey, an error matrix (sometimes referred to as confusion matrix) was compiled, showing field data versus automated classification output. Overall accuracy of the classification, producer's and user's accuracy and Kappa Coefficient were calculated from this error matrix.

Post classification comparison was carried out for the two independent images (thematic maps), which is the most proven technique to deal with change detection [24]. Difference or change information is generated by comparing image values of one data set (TM 1984) with those of the corresponding layer of the second data set $(E T M+2003)$. The ERDAS modeler is used to detect LCC between the two datasets [25]. There were 36 change categories, corresponding to the transition from each of the six classification categories of the one date to each one of the other date (including “no-change”). A 'conversion matrix' between TM 1984 versus ETM+ 2003 was compiled in the form of a contingency table. This conversion matrix was used to quantify LCC in terms of pixel values, ha or percentage of area coverage.

\section{Results and Discussion}

\subsection{Results}

The results of classification accuracy assessment are shown in Table 2. The overall accuracy and the Kappa value of field data versus automated classification results were 88 and $85 \%$, respectively. The accuracy level of each true LC category is indicated in Table 3. 
Table 2. Error matrix of field data versus ETM+ 2003 showing classification accuracy of the true land cover (LC).

\begin{tabular}{cccccccc}
\hline $\begin{array}{c}\text { Automated } \\
\text { Classification Result }\end{array}$ & Agriculture & $\begin{array}{c}\text { Mixed } \\
\text { forest }\end{array}$ & $\begin{array}{c}\text { Pure } \\
\text { forest }\end{array}$ & Shrubland & Grassland & Total \\
\hline Agriculture & 29 & - & 1 & - & 3 & 33 \\
Mixed forest & 0 & 19 & - & - & - & 19 \\
Pure forest & 1 & - & 16 & - & - & 17 \\
Shrubland & 1 & - & 2 & 7 & 1 & 11 \\
Grassland & - & - & 3 & - & 21 & 24 \\
Total Observations & 31 & 19 & 22 & 7 & 25 & 104 \\
\hline
\end{tabular}

Table 3. The accuracy level of each true LC category.

\begin{tabular}{ccc}
\hline Land Cover Classes & Producer's accuracy (\%) & User's accuracy (\%) \\
\hline Agriculture & 93.6 & 87.9 \\
Mixed natural forest & 100.0 & 100.0 \\
Pure forest & 72.7 & 94.1 \\
Shrubland/young trees & 100.0 & 63.6 \\
Grassland & 84.0 & 87.5 \\
\hline
\end{tabular}

The overall accuracy and Kappa values were 88 and $85 \%$, respectively. The classification of shrubland and mixed natural forest showed that $100 \%$ producer's accuracy, which means no pixel was incorrectly excluded from its category. However, agriculture, pure forest and grassland showed the omission of 6.4, 17.3 and 16\%, respectively. Mixed natural forest showed 100\% user's accuracy indicating accurately automated classification was carried out, whereas shrubland is less accurately classified $(63 \%)$ in automated classification.

Two LC maps and one change map were produced for visual display of different LC categories (Figure 2). On the classified map of TM 1984 and ETM+ 2003 images, the shadow/unclassified part was included as a separate class in Figures $2 \mathrm{a}$ and b. In the LCC map, the shadow/unclassified category was excluded, because the focus of the study was LCC, i.e., the change of true land cover.

Six categories were identified in each of the images of the two acquisition dates. Five categories can be regarded as true LC classes, namely: mixed forest, pure forest, shrubland, grassland and agriculture. One category was stated as shadow (unclassified) category. All the six categories (five true LC classes and one unclassified category) generated a total of 36 possible combinations or transformations, including the six identity transformations (no change). The total area of the SMNP under this study was estimated at about 13,907 ha (154,526 pixels). From the total area of the park, 90,331 pixels (58.5\% of the area) remained unchanged and $41.5 \%$ of the area changed from one category to another within 20 years (Figure 2(c)). 
Figure 2. LC maps of: (a) 1984, (b) 2003 and (c) land cover change (LCC).

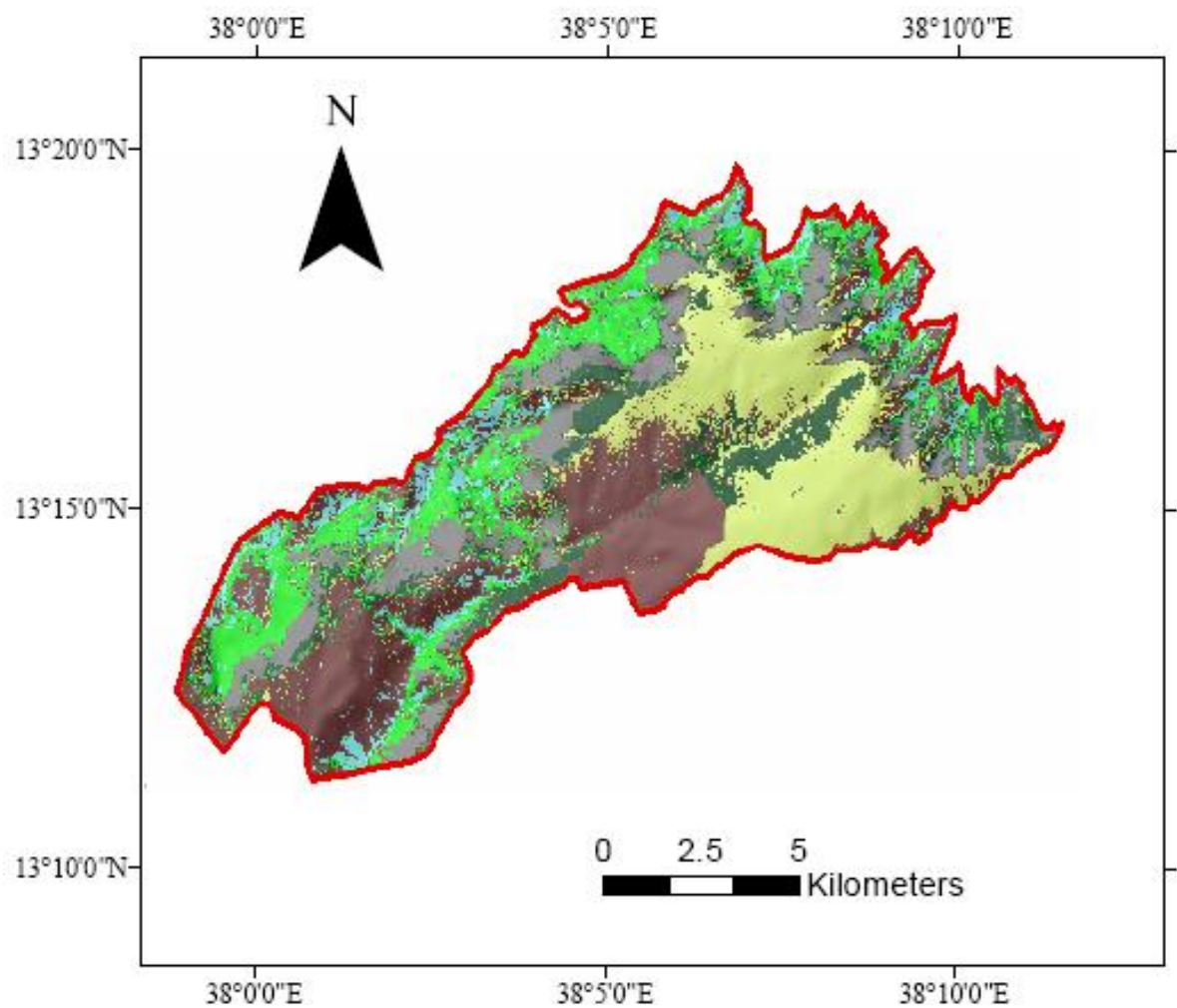

(a)

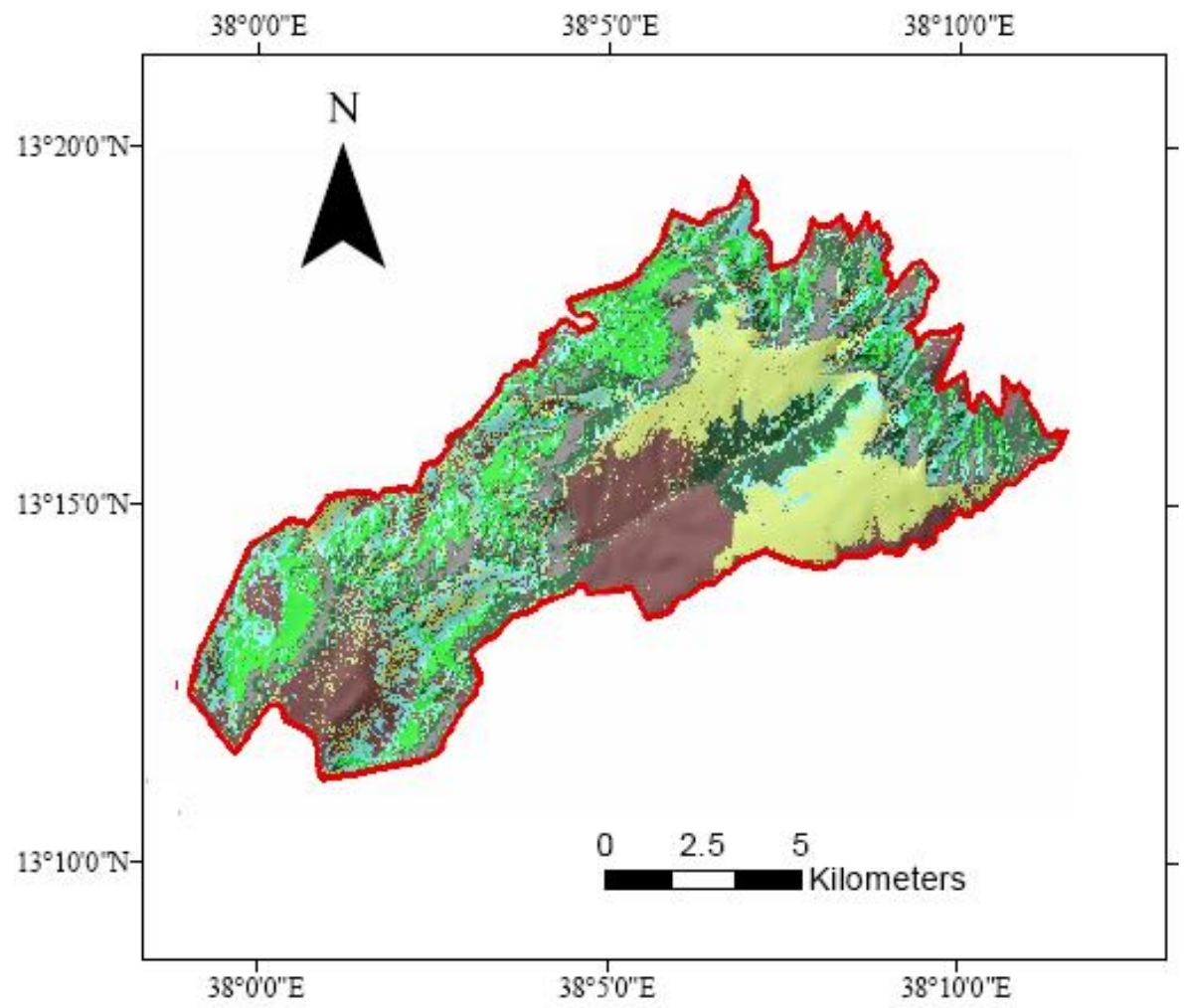

(b)

(b)

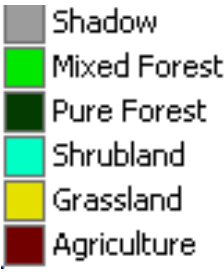

Shadow Mixed Forest Pure Forest Shrubland Grassland Agriculture 
Figure 2. Cont.
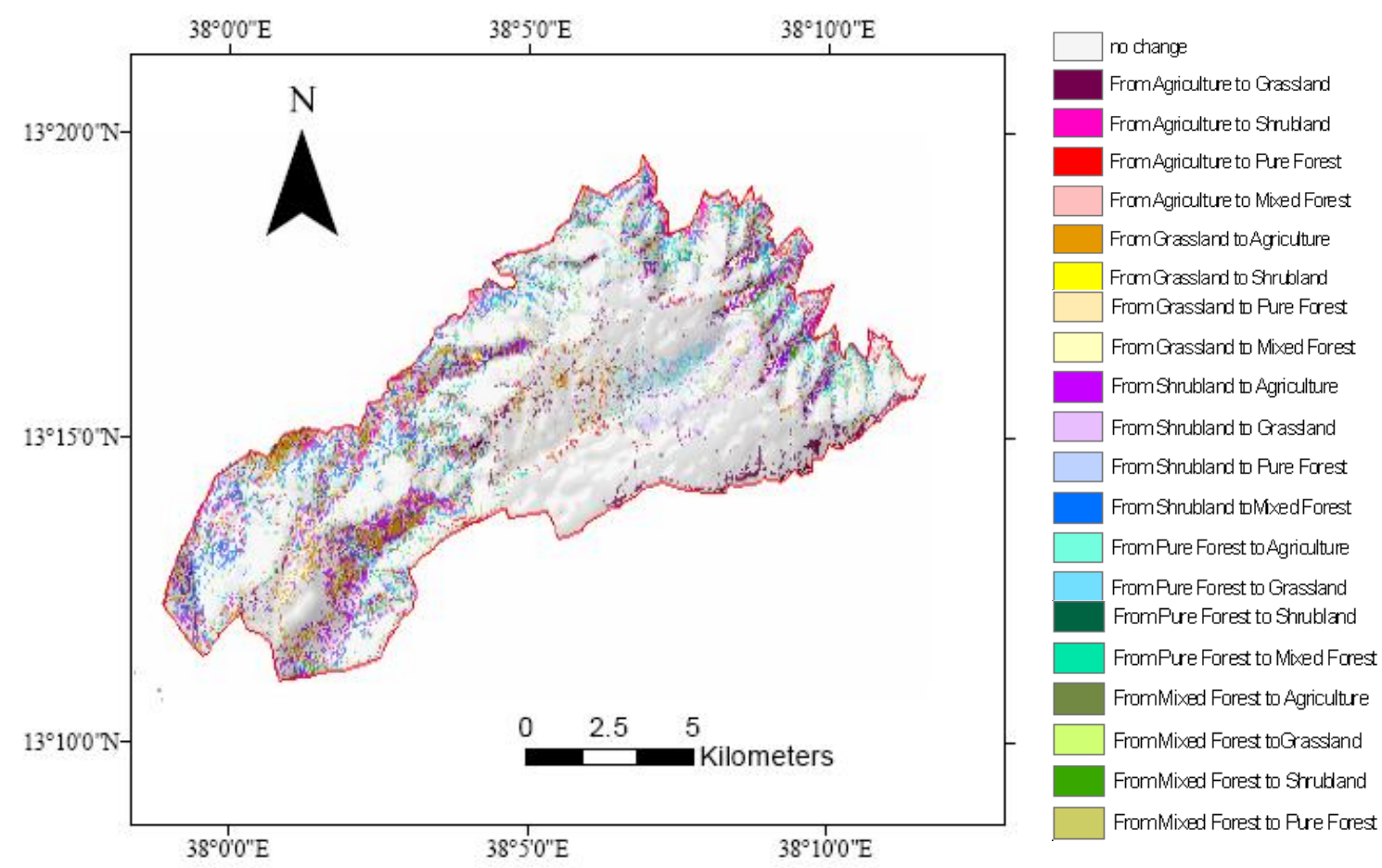

(c)

\subsection{Discussion}

In the year 1984, the LC categories arranged in order of increase in extent were the shrubland, pure forest, shadow, mixed natural forest, grassland and agricultural land. But, in the 2003 categorization, the result changed due to shift of one category to another, i.e., mixed forest, pure forest, shrubland, grassland and agriculture land (in the order of increase). This shift showed dynamicity of LC categories over time. It is known that agriculture and grazing are the main livelihood strategies of the population living in and around the SMNP. In 1984, grassland and agriculture in combination covered 50.26\% of the SMNP. Agriculture followed by grassland were the top two dominant LC classes of the SMNP both in 1984 and in 2003 (Figure 3). The overall area of forest and shrubland increased in spite of the intensive management of the park by agriculture and grazing (Figure 4). The increase may be due to the decrease of the shadow area from 1984 to 2003, regulations of the abandonment of the land from agriculture through government intervention and land fallowing due to decline of the soil fertility.

The percentage of the study area covered by pure forest and shrubland increased from 1984 to 2003. Pure forest increased from 11.71 to $15.63 \%$ of the total cover area, which means increase by $33 \%$ of 1984 cover (Figure 4). Erica species dominated forest increased particularly at the "Gich" plateau due to protection of the forest of the park and limited disturbance. The largest expansion was observed in the category of shrubland/young forest. It covered $7.34 \%$ of the total area of the park in 1984. In 2003, it expanded to $16.61 \%$ which is more than twice the cover of the year 1984 . The net gain of shrubland was $126 \%$ of that in the year 1984 . The overall percentage of grassland remained relatively unchanged. But, agricultural land decreased with a net loss of 683.82 ha between 1984 and 2003. The increases in 
forest cover and diminishing of agricultural land have positive contribution to wildlife habitat and protection of the natural resources. The conversion of one land cover to another is indicated in Figure 5.

Figure 3. Land cover classes of the Simen Mountains National Park (SMNP) in 1984 and 2003.

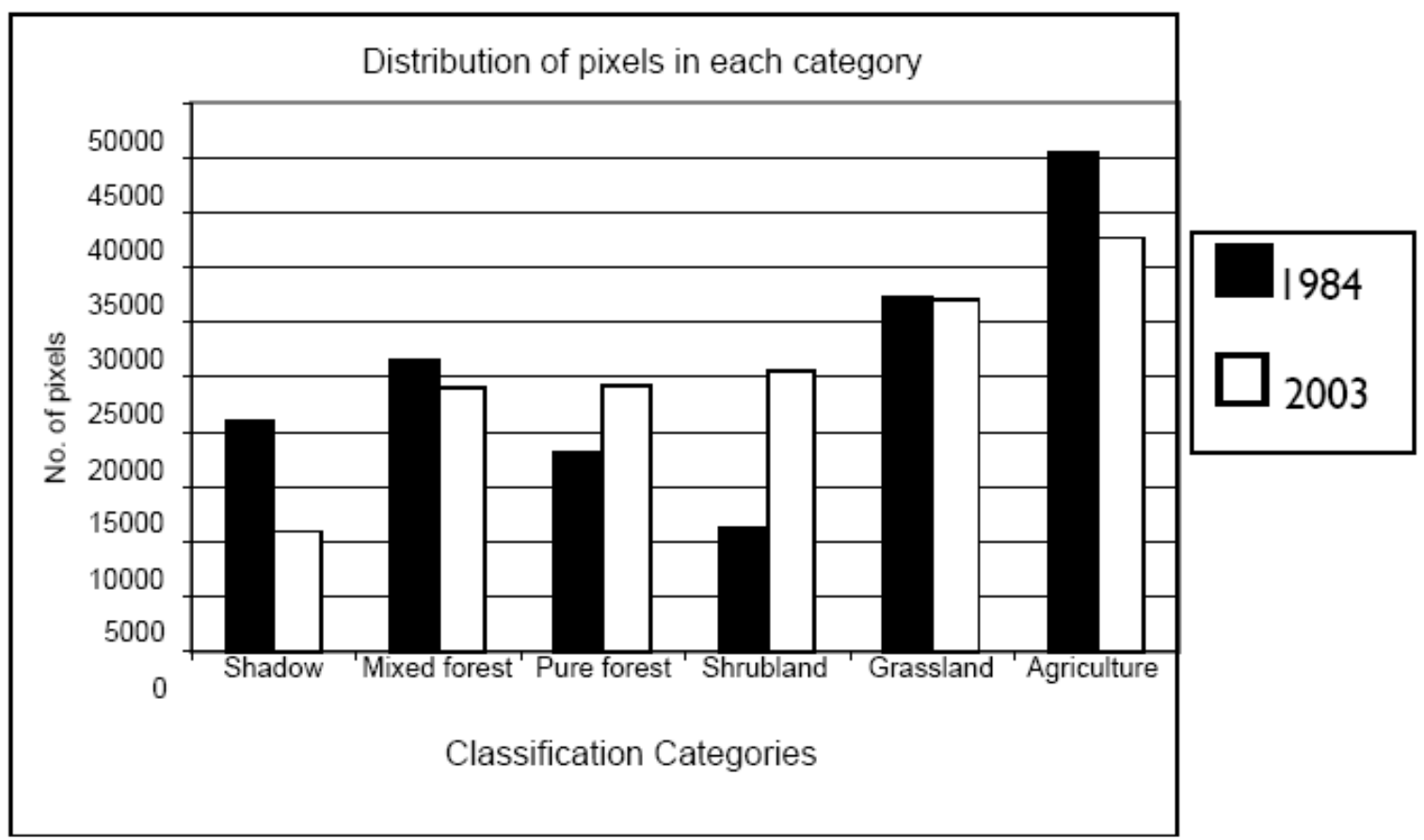

Figure 4. Trend (gain or loss) of the land cover.

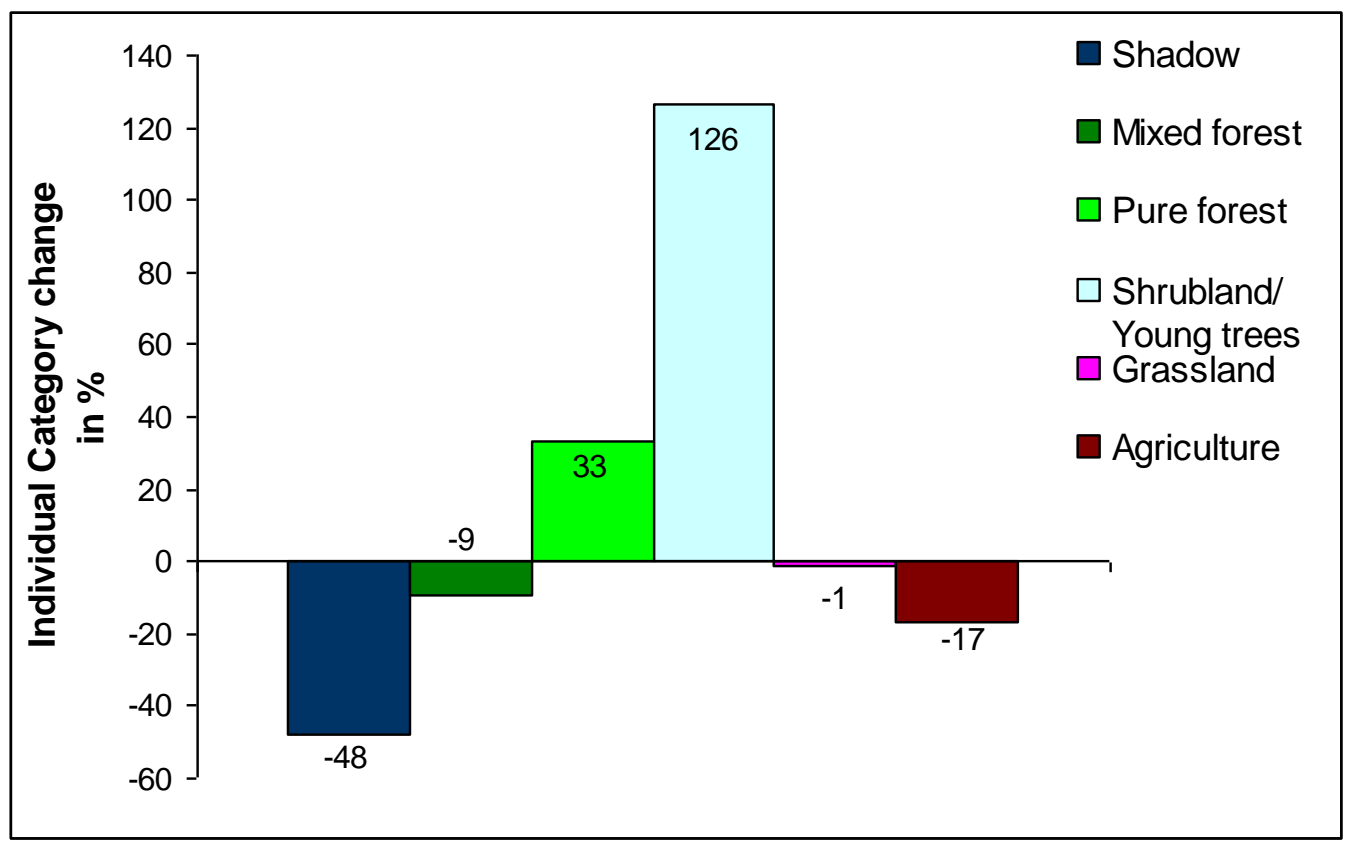

Agriculture, mixed natural forest and grassland are the major contributors for the increase of shrubland coverage. Agriculture contributed $18 \%$ for the increase of the shrubland/young forest.

The Landsat images proved notably useful in analysis of the ecological changes on a time-series basis and can be used for planning measures for restoration of the SMNP ecosystem. To meet the 
objectives of the SMNP, wildlife habitats, conservation sites, and management units can be identified and delineated with the help of GIS and RS to set up development strategies, design management activities and make decision on natural resources management. The output can be used as a basis for future conservation, management and land development strategies.

Figure 5. Direction of change of one LC to another.

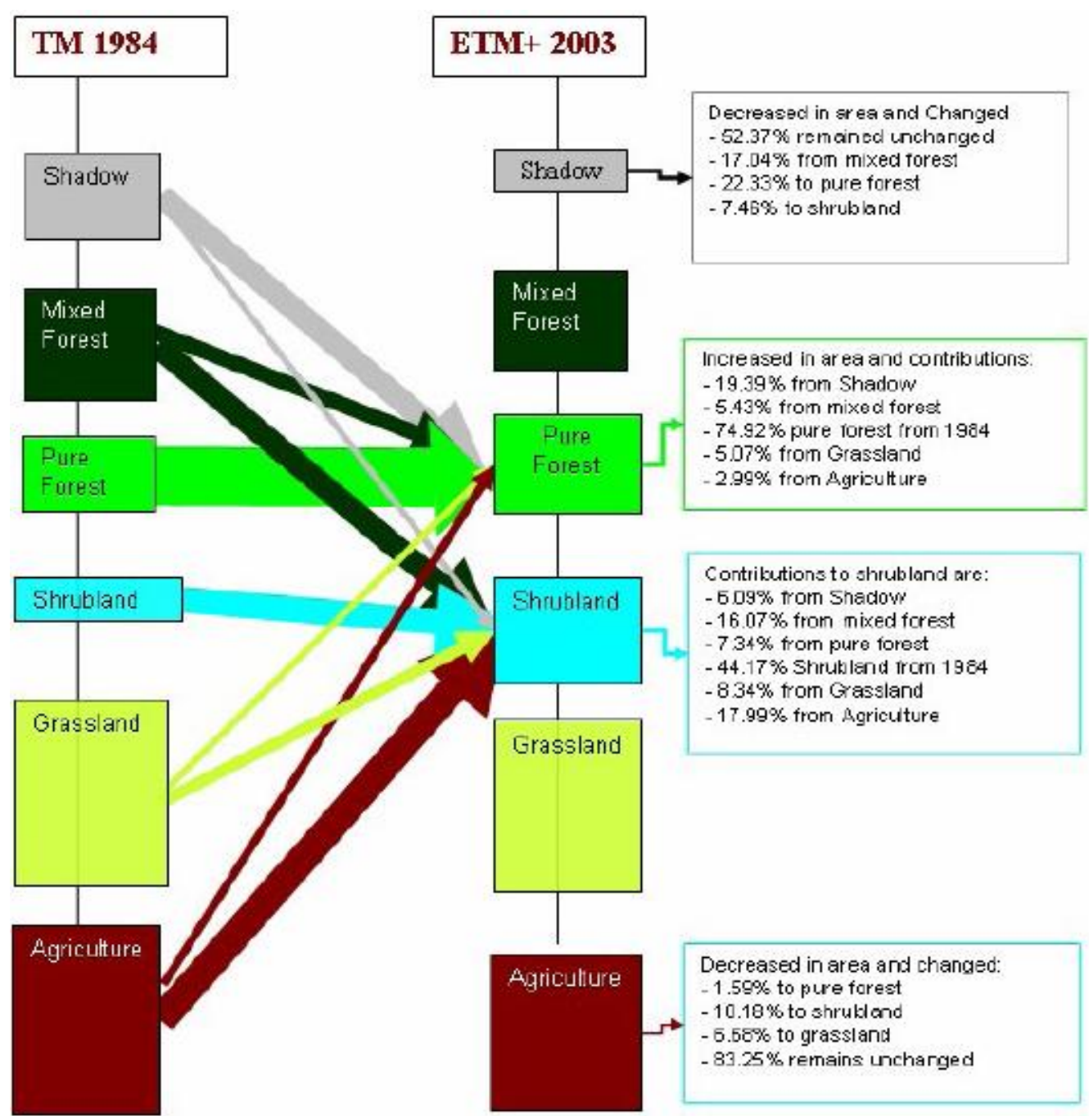

Using Landsat TM 1984 and ETM+ 2003 datasets, LCC was detected to understand the trend/direction of the natural resources mainly of the land cover. The result showed that integration of GIS and RS is effective in monitoring the overall status of the SMNP. The quantitative evidence of land cover dynamics showed that the forest cover increased from 1984 to 2003 in spite of the increase of human and animal population of the SMNP. The human and animal population is said to have increased in the last five decades. However, the result of the study indicated that agricultural areas and grassland, which form the economic basis for the people, have decreased and relatively remained unchanged, respectively, between 1984 and 2003. This can be attributed to the biophysical nature of the SMNP, regulatory rules of both National Regional and Federal Governments, international organizations and, probably, land fallowing due to decline of the soil fertility. Therefore, it is not only the socio-economic situation that has a direct impact on the dynamics of the LC, but also the 
biophysical nature of the area. In general, the spatial distribution of the individual LC classes is the result of human intervention and biophysical influences.

\section{Conclusions}

Five land cover categories are successfully classified and the shadow remained unclassified. The classified categories were shown with their spatial distribution over time. Our results provide a springboard to identify the LCC and an overall picture of the SMNP, which can serve as a hint to anticipate the trend of land cover, mainly the forest cover. LCC also has an impact on the Afroalpine ecosystem, which is the most important part of the national park as a habitat for the endangered species. However, the shadow was stated as unclassified category. Further investigation on the unclassified land cover categories, such as the shadow areas have to be incorporated in further research and development programs designed for the park. These areas could be hot spot areas as wildlife habitats, mainly, of birds, mountain climbing animals and highland forest species. Although settlements have direct correlation to LCC, they were not successfully classified due to the limited spatial resolution of the Landsat images and the pattern of settlements. Similarly, cliffs or the land cover class of so-called "unusable land" as discussed in the study of Hurni and Ludi [18] could not be recognized in the present study. There is a limitation to comparative study of the land cover change using aerial photos and Landsat images owing to time and resource constraints. It was difficult to address long term changes from the year in which SMNP was gazetted up to the present time. Therefore, inclusion of all these data would help to show the long time trend of the resources and to predict and model the future status of the SMNP. Trend information is recommended from the year 1969 to the present time in order to have a clearer and continuous database to further facilitate policy decisions.

Analysis and display of LC and LCC in this study indicate the overall situation and highlight the trends of the SMNP in terms of the LC. Therefore, our results can provide basic information for efficient and effective monitoring of LC in relation to wildlife habitat conditions. The resource managers can superimpose the land cover map to existing management and conservation zone maps and use it as a planning tool for the optimization of protection sites within the park, providing information on the status of wildlife and natural resources. Furthermore, the LC map can provide information as an indicator of the overall environmental quality and direction of change of the SMNP over the given time. Environmental parameters may be used as hints to plan the restoration of the park and to support strategic decisions for conservation and development policy.

Remotely sensed data have a limitation: they provide information on land cover, but they cannot provide information on 'land use', which relates to the human (economic and cultural) activities utilizing and influencing land cover. Combined analyses of field observations, socio-economic and remotely sensed data are recommended to have a better output in terms of land use (LU) information. This can provide better information on the inherent characteristics of LC and LU classes and give a better overview on the status of the SMNP.

Although the energy source of the local people is wood-based, the overall annual rate of forest increased, which is different from the general situation in Ethiopia. This figure might mask the ecological status of different endangered species. LC map can be used to visualize the status of the 
SMNP by both local people and policy makers so that they can feel the changes and suggest the possible solutions. RS, with Landsat images, can detect the coarse scale status and change. However, it may overlook fine-scale changes, e.g., a fine-scale fragmentation of the ecosystem. Grazing cattle can have significant impact on vegetation, birds, mammals, and water, without being recognized by the remote sensing methods applied here. Therefore, it is recommended to identify the status of the habitat of wildlife, trend of the numbers of endemic and rare species as well as management and conservation strategies in relation to LCC with terrestrial methods.

The change detection showed that shrubland/young forest area has increased. This may be due to the abandonment of agricultural and grazing land. This evidence, in turn, indicates that the government restrictions on agricultural practice within the park have been important in mitigating the pressures of wildlife conservation and management over the last two decades: There is a reduction of agricultural land, and almost no expansion of grazing land. But, the LCC should correlate with the objective of SMNP related to conservation of endangered wildlife and endemic species and conservation of biodiversity. Furthermore, off farm activities should be considered to improve the livelihood of farmers so that the fragile ecosystem is maintained and the situation of natural resources is improved.

Land use activities could not be explained by image analysis in this study. Only the physical features of the park are displayed and analyzed mainly cover categories. Therefore, further investigations on the inherent characteristics of different LC classes have to be carried out. Further investigations of the combination of remote sensing with data on the trend of human and animal populations, economic activities, the social and cultural importance of the region, and policy issues would be helpful in solving conservation and management problems and designing future development strategies.

It is important to prevent or take measures against further expansion of settlements, which might have a negative impact on wildlife habitats. Limiting settlement expansion may help to manage and conserve the wildlife and the fragile ecosystem. Consensus-based compromises are needed among the stakeholders to facilitate both policy issues and management strategies in relation to land and land cover changes in SMNP.

\section{Acknowledgements}

Austrian Foreign Exchange Service (Österreichischer Austauschdienst, ÖAD) is highly acknowledged for covering all the financial expenses of the study. Franz Suppan is acknowledged for technical support and guidance in remote sensing part of the study. Our thanks go to Adet Agricultural Research Center for logistic and office facility support. We are very grateful to farmers of the SMNP for their hospitality during field work.

\section{References}

1. Goldewijk, K.; Ramankutty, K. Land cover change over the last three centuries due to human activities: The availability of new global data sets. Geojournal 2004, 61, 335-344.

2. Manson, S.M. Agent-based modeling and genetic programming for modeling land change in the Southern Yucatán Peninsular Region of Mexico. Agr. Ecosyst. Environ. 2005, 111, 47-62.

3. Scholes, R.J.; Breeman, N. The effects of global change on tropical ecosystems. Geoderma 1997, 79, 9-24. 
4. Velazquez, A.; Elvira, D.; Ramirez, I.; Mas, J.; Bocco, G.; Ramirez, G.; Palacio, J. Land use-cover change processes in highly biodiverse areas: The case of Oaxaca, Mexico. Glob. Environ. Change 2003, 13, 175-184.

5. Kintz, D.B.; Young, K.R.; Crews-Meyer, K.A. Implications of land use/land cover change in the buffer zone of a national park in the tropical andes. Environ. Manage. 2006, 38, 238-252.

6. Lopez, E.; Bocco, G.; Mendoza, M.; Velazquez, A.; Axguirre-Rivera, J.R. Peasant emigration and land-use change at the watershed level: A GIS-based approach in Central Mexico. Agr. Syst. 2006, 90, 62-78.

7. Xiao, J.; Shen, Y.; Ge, J.; Tateishi, R.; Tang, C.; Liang, Y.; Huang, Z. Evaluating urban expansion and land use change in Shijiazhuang, China, by using GIS and remote sensing. Landscape Urban Plan. 2006, 75, 69-80.

8. Wu, Q.; Li, H.; Wang, R.; Paulussen, J.; He, Y.; Wang, M.; Wang, B.; Wang, Z. Monitoring and predicting land use change in Beijing using remote sensing and GIS. Landscape Urban Plan. 2006, 78, 322-333.

9. Giri, C.; Zhu, Z.; Reed, B. A comparative analysis of the Global Land Cover 2000 and MODIS land cover data sets. Remote Sens. Environ. 2007, 94, 123-132.

10. Melesse, A.M. Spatiotemporal dynamics of land surface parametres in the Red River of the North Basin. Phys. Chem. Earth 2004, 29, 795-810.

11. Wondie, M. Study on Spatial and Temporal Land Cover Changes Using Geographical Information System (GIS) and Remote Sensing in the Simen Mountains National Park, Northwestern Ethiopia. M.Sc. Thesis, University of Natural Resources and Applied Life Sciences, Vienna, Austria, 2007.

12. Tso, B.; Mather, P. Classification Methods for Remotely Sensed Data; CRC Press: Boca Raton, FL, USA, 2007.

13. Hathout, S. The use of GIS for monitoring and predicting urban growth in East and West St Paul, Winnipeg, Manitoba, Canada. J. Environ. Manag. 2002, 66, 229-238.

14. Burnnett, C.; Fall, A.; Temppo, E.; Kalliola, R. Monitoring current status of and trends in boreal forest land use in Russian Karelia. Conserv. Ecol. 2003, 7, 8.

15. Yirdaw, E. Restoration of the Native Woody-Species Diversity, Using Plantation Species as Foster Trees, in the Degraded Highlands of Ethiopia. Ph.D. Dissertation, University of Helsinki, Helsinki, Finland, 2007.

16. Tatem, A.J.; Lewis, H.G.; Atkison, P.M.; Cixon, M.S. Increasing the spatial resolution of agricultural land cover maps using a Hopfield neural network. Int. J. Geogr. Inform. Syst. 2003, 7, 647-672.

17. Edroma, E.L.; Smith, K.H. Monitoring Mission Report to Simen Mountains National Park and World Heritage Site, Ethiopia; UNESCO and IUCN the World Heritage Centre: Paris, France, 9-14 April 2001.

18. Hurni, H.; Ludi, E. Reconciling Conservation with Sustainable Development: A Participatory Study inside and around the Simen Mountains National Park, Ethiopia; Center for Development and Environment (CDE), University of Bern: Bern, Switzerland, 2000. 
19. Hurni, H. Management Plan: Simen Mountains National Park and Surrounding Rural Area; UNESCO World Heritage Committee and Wild Life Conservation Organization: Addis Ababa, Ethiopia, 1986.

20. Earth Science Data Interface at the Global Land Cover Facility. Available online: http://glcfapp.umiacs.umd.edu:8080/esdi/esdi_index.jsp (accessed on 4 January 2007).

21. Amsalu, A.; Stroosnijder, L.; de Graaff, J. Long-term dynamics in land resource use and the driving forces in the Beressa watershed, highlands of Ethiopia. J. Environ. Manag. 2007, 83, 448-459.

22. NASA Landsat Program. Landsat ETM+ scene L71008058_05820031026, SLC-Off; USGS: Sioux Falls, SD, USA, 26 October 2003. Available online: http://srtm.csi.cgiar.org (accessed on 4 January 2007).

23. Lillesand, T.M.; Kiefer, R.W. Remote Sensing and Image Interpretation, 4th ed.; John Wiley and Sons, Inc.: Hoboken, NJ, USA, 2000.

24. Shalaby, A.; Tateishi, R. Remote sensing and GIS for mapping and monitoring land cover and land-use changes in the Northwestern coastal zone of Egypt. Appl. Geogr. 2007, 27, 28-41.

25. ERDAS Imagine. ERDAS IMAGINE® Tour Guides ${ }^{\mathrm{TM}}$; ERDAS: Atlanta, GA, USA, 2006.

(C) 2011 by the authors; licensee MDPI, Basel, Switzerland. This article is an open access article distributed under the terms and conditions of the Creative Commons Attribution license (http://creativecommons.org/licenses/by/3.0/). 